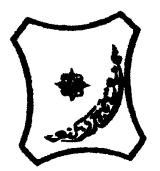

Bayero Journal of Pure and Applied Sciences, 10(1): 376 - 382

ISSN 2006 - 6996

\title{
BIODEGRADATION OF DIMETHYLFORMAMIDE USING Bacillus cereus ISOLATED FROM SOILS CONTAMINATED WITH TEXTILE EFFLUENT IN KANO
}

\author{
${ }^{1}$ Amina, O.Z. and ${ }^{2}$ Kawo, A.H. \\ ${ }^{1}$ Biology Department, Federal College of Education Kano PMB 3045, Kano. \\ ${ }^{2}$ Department of Microbiology, Bayero University, Kano PMB, 3011, Kano \\ ${ }^{*}$ Corresponding author: shazymeena02@gmail.com 08036865847
}

\begin{abstract}
The study was conducted to investigate the potential of Bacillus cereus isolated from soil contaminated with textile effluent in degrading dimethylformamide (DMF). The bacterial isolate was inoculated into minimal broth containing different concentrations of DMF like 50, 100, 150 and $200 \mu \mathrm{l}$. Biodegradation was confirmed by analyzing the optical density, $\mathrm{pH}$, biomass, carbon dioxide and ammonia production measured at intervals of 48 hours for 10days. Bacillus cereus was found to be efficient in degrading DMF as a result of an increase in $\mathrm{pH}$, optical density, biomass, $\mathrm{CO}_{2}$ and $\mathrm{NH}_{3}$ gas production from the $4^{\text {th }}$ up to the $10^{\text {th }}$ day of treatment with DMF. Highest utilization of DMF was seen on the $6^{\text {th }}$ day, $(0.48$ at $600 \mathrm{~nm})$ for optical density, on the $8^{\text {th }}$ day $(1.45 \mathrm{~nm})$ for ammonia gas produced, on the $4^{\text {th }}$ day, $(0.95 \mathrm{mg} / \mathrm{L})$ for carbon dioxide produced, on the $8^{\text {th }}$ day $\left(0.85 \mathrm{gdry}\right.$ weight/L), and on the $10^{\text {th }}(9.20)$ for $\mathrm{pH}$. The biodegradation efficiency was more at $40^{\circ} \mathrm{C}$ than at ambient temperature. This showed that Bacillus cereus can be used in the biodegradation of DMF from textile effluent.

Keywords: Bacillus cereus, Biodegradation, Efficiency, Dimethylformamide, Textile effluent
\end{abstract}

\section{INTRODUCTION}

Industrialization is important in the economic development of an underdeveloped country. The historical facts reveal that all the developed countries of the world broke the vicious circle of underdevelopment by industrialization. Water on the other hand is our lifeline that bathes us and feeds us. In ancient cultures water represented the very essence of life. There is increasing demand for water and decrease in it's supply (Bromley et al., 2002). Therefore, it is important to treat and reuse industrial effluent. However, there are associated problems resulting from the introduction of industrial waste products into the environment. Many of these products are problematic because of persistence (low biodegradability) and/or toxicity. The textile industry is one of the many industries that utilize large volumes of water in the manufacturing process. The textile industries produce effluents that contain several types of chemicals such as dispersants, leveling agents, acids, alkalis, carriers and various dyes (Bromley et al., 2002).

Textile effluents are of concern because they color the drains and water bodies and consequently diminish the water quality (Long et al., 2001). In many Nigerian cities, the textile factories daily discharge millions of liters of untreated effluents in the form of wastewater into public drains that eventually empty into rivers (Long et al., 2001).

Being a versatile organic solvent, N, Ndimethylformamide (DMF) is widely used in several industrial applications. It is primarily used as a solvent in the production of polyurethane products and acrylic fibers (Vidhya et al; 2012). It is a colorless liquid with a faint amine odor. Manufacturers use DMF as a solvent in a variety of applications, including textile coatings, production of electronic components and pharmaceutical products (Pellizzari, 1977). As most of the DMF is released into the effluents after recovering the solute, it is regarded as one of the most common chemical found in the industrial effluents (USEPA, 1986). In view of the established reports on its widespread occurrence and its adverse impacts on the environment and health, the DMF is considered to be an increasing threat both for the environment and to humans (Kennedy et al., 1986). 
DMF is a possible product of the photochemical degradation of dimethylamine and trimethylamine (Olayinka et al., 2004). Both are commonly occurring natural substances and are also used in industrial applications. DMF does not occur naturally. There are few data concerning environmental levels or the exposure of the general population to DMF. Concentrations in the air in the range of $0.02-0.12 \mathrm{mg} / \mathrm{m} 3$ have been found in residential areas, near industrial sites (Vidhya et al; 2012). DMF is released in to the environment through various ways. When emitted into air, most of the DMF released remains in that compartment, where it is degraded by chemical reactions with hydroxyl radicals. Indirect releases of DMF to air (Vidhya et al; 2012), such as transfers from other environmental media, play only a small role in maintaining levels of DMF in the atmosphere. When DMF is released into water, it degrades there and does not move into other media. Contamination of soil with DMF may occur through spillage or leakage during its production, transport, storage, or use. When released into soil, most of the DMF remains in the soil presumably in soil pore water until it is degraded by biological and chemical reactions. If DMF reaches groundwater, its anaerobic degradation will be slow (Dojlido, 1979). The toxicity of DMF has been studied in many species, by various administration routes with generally similar results Hepatotoxicity has been reported in most species studied, including humans, following both acute and sub chronic exposure The toxicity of DMF following inhalation exposure has been reasonably well characterized. Rats survived a single 4-hour exposure to saturated vapors of DMF, with a nominal concentration of approximately 5000 ppm (Dojlido, 1979).

Compared with chemical/physical methods, biological processes have received more interest because of their cost effectiveness, lower sludge production and environmental friendliness (Vidhya et al; 2012). Improvement in the ability of microorganisms to degrade a pollutant could be achieved through modification of the environment or the organisms. The ability of microorganisms to degrade and metabolize a wide variety of compounds has been recognized and exploited in various biotreatment processes. The biotreatment offers a cheaper and environmentally friendlier alternative for removal of pollutants in textile effluents (Smyth et al., 1948). In the present study an attempt has been made to isolate a bacterial strain, capable of degrading DMF and to identify and determine its efficiency of degradation by analyzing different parameters like $\mathrm{pH}$, turbidity, biomass, $\mathrm{CO} 2$ production and ammonia production.

\section{MATERIALS AND METHODS \\ Collection of sample}

Soil samples contaminated with textile industry effluent containing dimethylformamide at Sharada industrial area were collected in sterile screw capped bottles.

\section{Isolation of DMF Degrading Bacteria}

A stock solution of $1 \mathrm{~g}$ textile effluent contaminated soil to $9 \mathrm{ml}$ distilled water was serially diluted and $0.1 \mathrm{ml}$ from the $10^{-6}$ dilution was taken and spread on minimal medium $(1.8 \mathrm{~g}$ $\mathrm{Na}_{2} \mathrm{HPO}_{4} .7 \mathrm{H}_{2} \mathrm{O}, \quad 1.2 \mathrm{~g} \quad \mathrm{~K}_{2} \mathrm{HPO}_{4}, \quad 4 \mathrm{~g} \quad \mathrm{NH}_{4} \mathrm{Cl}, \quad 0.2 \mathrm{~g}$ $\mathrm{MgSO}_{4} .7 \mathrm{H}_{2} \mathrm{O}, 0.1 \mathrm{~g} \mathrm{NaCl}, 0.01 \mathrm{~g} F \mathrm{FeSO}_{4} .7 \mathrm{H}_{2} \mathrm{O}, 20 \mathrm{~g}$ plain agar, $0.1 \mathrm{mg} / \mathrm{L}$ ketoconazole) containing $50 \mu \mathrm{l}$ of DMF as a sole carbon source. The plate was incubated in an incubator aerobically at $37^{\circ} \mathrm{C}$ for a week (Vidhya et al., 2012).

\section{Identification of DMF Degrading Bacteria}

The bacterial isolate was subjected to Gram's staining and biochemical tests like Methyl red, Voges proskauer, citrate utilization, oxidase, catalase, indole production, urease, Triple Sugar Iron agar, sporulation tests were carried out for tentative identification of the bacterial isolate as described by Nagoba et al., 2012.

\section{Degradation Efficiency}

The bacterial isolate was inoculated on minimal broth containing 50, 100, 150 and 200 $\mu \mathrm{l}$ concentration of DMF. The tubes were incubated at ambient temperature and at $40^{\circ} \mathrm{C}$ and the degradation of DMF by the bacterium was confirmed by analyzing the optical density, $\mathrm{pH}$, biomass of the medium and carbon dioxide and ammonia production. These parameters were measured every 48hours for 10 days (Vidhya et al., 2012).

$\mathrm{pH}$

The $\mathrm{pH}$ of the sample was measured after $4,6,8$ and 10 days of incubation using $\mathrm{pH}$ meter (Vidhya et al., 2012).

Optical Density

The optical density of the samples were obtained by using spectrophotometric method as described by Vidhya et al. (2012).

\section{Biomass Estimation}

The biomasses were estimated by centrifuging the biodegraded samples. The pelleted biomass was taken by measuring on weighing scale (Vidhya et al. 2012). 


\section{Carbon dioxide Estimation}

The carbon dioxide produced was estimated by volumetric method using barium hydroxide as described by Amela et al. (2008). Carbon dioxide reacts with barium hydroxide to form barium carbonate precipitate. The precipitate form is collected dried and measured and used in the estimation of carbon dioxide produced during the degradation process.

$\mathrm{Ba}(\mathrm{OH})_{2}+\mathrm{CO}_{2} \longrightarrow \mathrm{BaCO}_{3}$ (ppt)

Ammonia Estimation

Two to three drops of Nessler's reagent were added to $1 \mathrm{ml}$ of the sample during of degradation of DMF and the color change noted. Concentration of ammonia was estimated using colorimeter (American Public Health Association, 1992). Ammonia ions react with Nessler's reagent to form a precipitate of mercury II amido iodide. The colour of the precipitate varies from yellow to brown depending on the quantity of ammonium ions. This is used to identify traces in ammonia present in a solution.

$\mathrm{NH}_{4}+2\left(\mathrm{Hgl}_{4}\right)^{2-}+4 \mathrm{OH} \longrightarrow \mathrm{HgO} \mathrm{Hg}\left(\mathrm{NH}_{2} \mathrm{I}\right)_{(\mathrm{s})}+$ $7 \mathrm{I}+3 \mathrm{H}_{2} \mathrm{O}$

(Yellow/Brown)

Statistical analysis

Two ways ANOVA was performed for the data generated using Microsoft Excel. Variability was considered significant only when the statistical value was greater than the tabulated value at $P$ is less than or equal to 0.05 (Vidhya et al; 2012).

\section{RESULTS AND DISCUSSION}

Isolation and Identification

The bacterial isolate from the soil was identified as Gram positive rod. Then the isolate was tentatively identified as Bacillus cereus on the basis of results obtained from biochemical tests (Table 1). The isolate was able to grow on minimal agar containing various concentrations of DMF.

Table 1: Biochemical tests for the identification of the isolates

\begin{tabular}{cll}
\hline S/N & Test & Reaction of Organism \\
\hline 1. & Gram staining & + Bacilli \\
2. & Methyl red & + \\
3. & Voges Proskauer & + \\
4. & Simmons citrate agar & + \\
5. & Catalase & + \\
6. & Oxidase & - \\
7. & Indole & - \\
8. & Urease & - \\
9. & Triple sugar iron agar & + \\
10. & Nitrate reduction & - \\
11. & Sporulation & + \\
& Inference & Bacillus cereus
\end{tabular}

(+ = Positive reaction, - = Negative reaction)

The changes in optical density determined after 4, 6, 8 and 10 days of treatment with Bacillus cereus at $\left(40^{\circ} \mathrm{C}\right)$ is shown in figure 1 . The optical density increased from the $6^{\text {th }}$ day of treatment with DMF and then later decrease on the $10^{\text {th }}$ day. Highest optical density was observed at $50 \mu \mathrm{l}$ concentration of DMF on the $6^{\text {th }}$ day of treatment. Increase in optical density is a result of increase in the growth of bacterium in the medium.

Changes in optimal density were found to be not significantly different $(P>0.05)$ throughout the duration of the analysis.

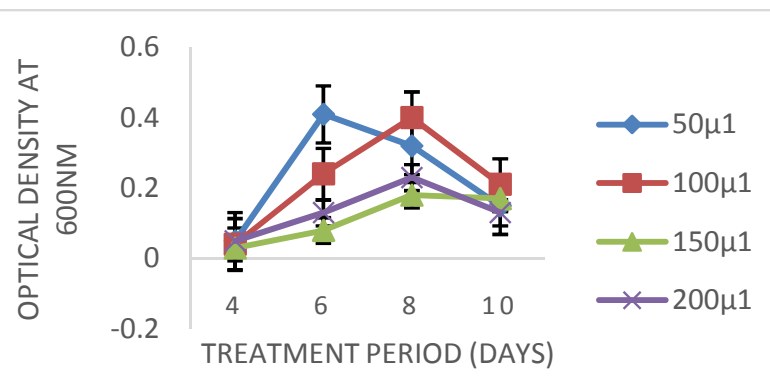

Figure 1: Changes in optical density during the degradation of DMF by Bacillus cereus at incubation temperature. 
Release of ammonia as a result of biodegradation of DMF by Bacillus specie is illustrated in figure 2 . The concentration of liberated ammonia was found to increase till the $10^{\text {th }}$ day of treatment. The maximum release of ammonia was observed during the $8^{\text {th }}$ day of treatment at $150 \mu l$ concentration of DMF. Increase in ammonia production by the bacterium is as result of increase in the utilization of dimethylformamide since ammonia is a byproduct of DMF degradation. Ammonia ions react with Nessler's reagent to form a precipitate of mercury II amido - iodide. The colour of the precipitate varies from yellow to brown depending on the quantity of ammonium ions. This is used to identify traces in ammonia present in a solution.

$\mathrm{NH}_{4}+2\left(\mathrm{Hgl}_{4}\right)^{2-}+4 \mathrm{OH} \longrightarrow \mathrm{HgO} \mathrm{Hg}\left(\mathrm{NH}_{2} \mathrm{I}\right)_{(\mathrm{s})}+$ $7 \mathrm{I}+3 \mathrm{H}_{2} \mathrm{O}$

(Yellow/Brown)

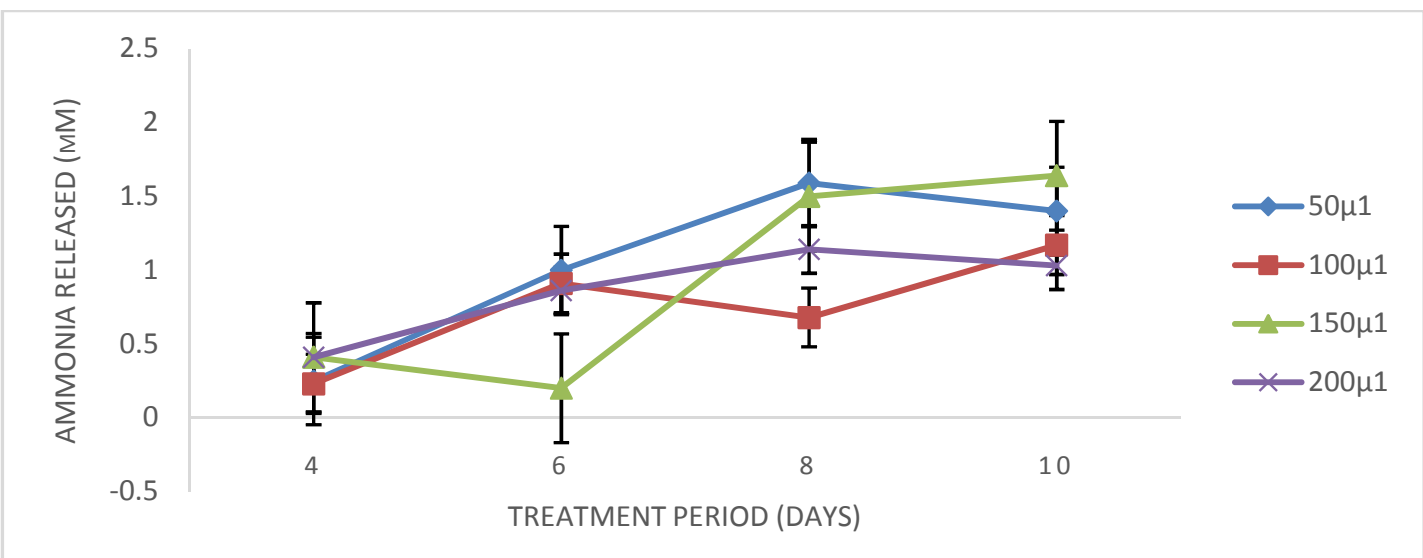

Figure 2: Ammonia released during the degradation of DMF by Bacillus at incubation temperature.

Changes in the Biomass during the degradation of DMF Bacillus specie at $40^{\circ} \mathrm{C}$ is seen in Figure 3. Growth of the bacterium was observed to increase to some extent and then a decrease was observed. Highest biomass was observed on the $6^{\text {th }}$ day of treatment at $150 \mu \mathrm{l}$. This indicates that the degradation of DMF increases as incubation period increases. Changes in Biomass were found to be not significantly different $(P>0.05)$ throughout the duration of the analysis.

The decrease in the biomass may be due to the formation of degraded products like dimethylamine and ammonia.

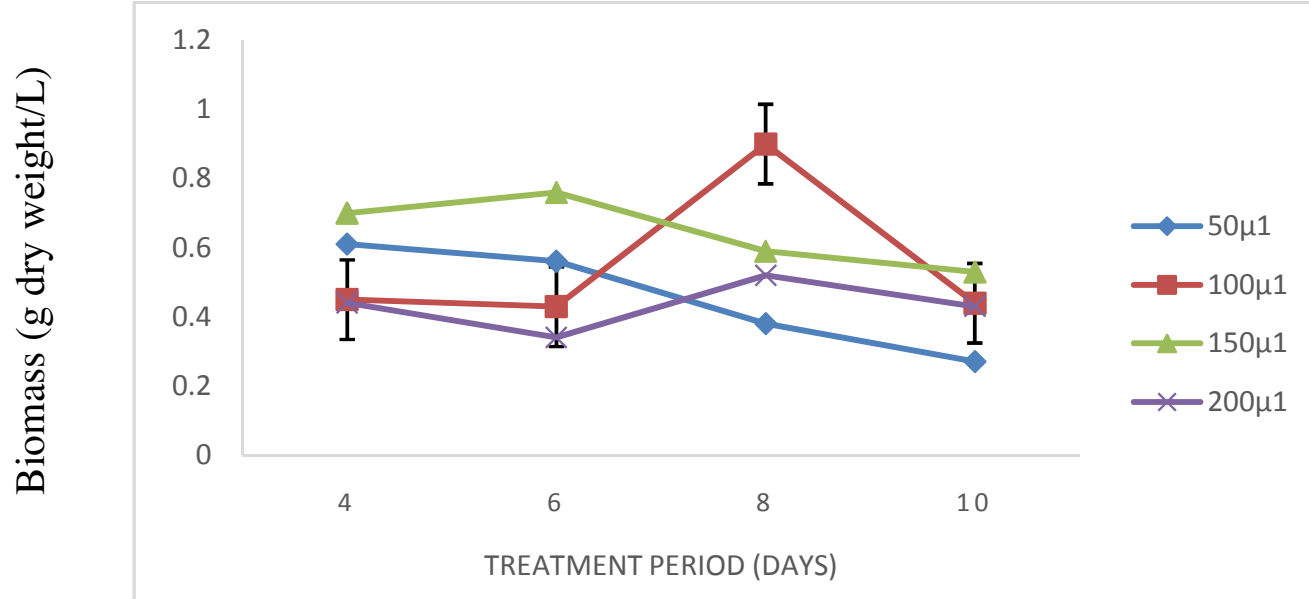

Figure 3: Changes in the Biomass during the degradation of DMF Bacillus specie at $40^{\circ} \mathrm{C}$ 
Also, changes in $\mathrm{pH}$ during the treatment period of biodegradation by Bacillus cereus at $40^{\circ} \mathrm{C}$ is illustrated in figure 4. During the degradation process, $\mathrm{pH}$ was found to increase gradually from the $4^{\text {th }}$ day to $10^{\text {th }}$ day of treatment. Highest was seen on the $8^{\text {th }}$ day at $200 \mu$ l concentration of DMF.
This increase in the $\mathrm{pH}$ may be due to the constant release of dimethylamine and ammonia into the medium. $\mathrm{pH}$ was found to increase from 7 to 9.2 .

Statistically, there was significant difference ( $P$ $<0.05$ ) in $\mathrm{pH}$ throughout the treatment period.

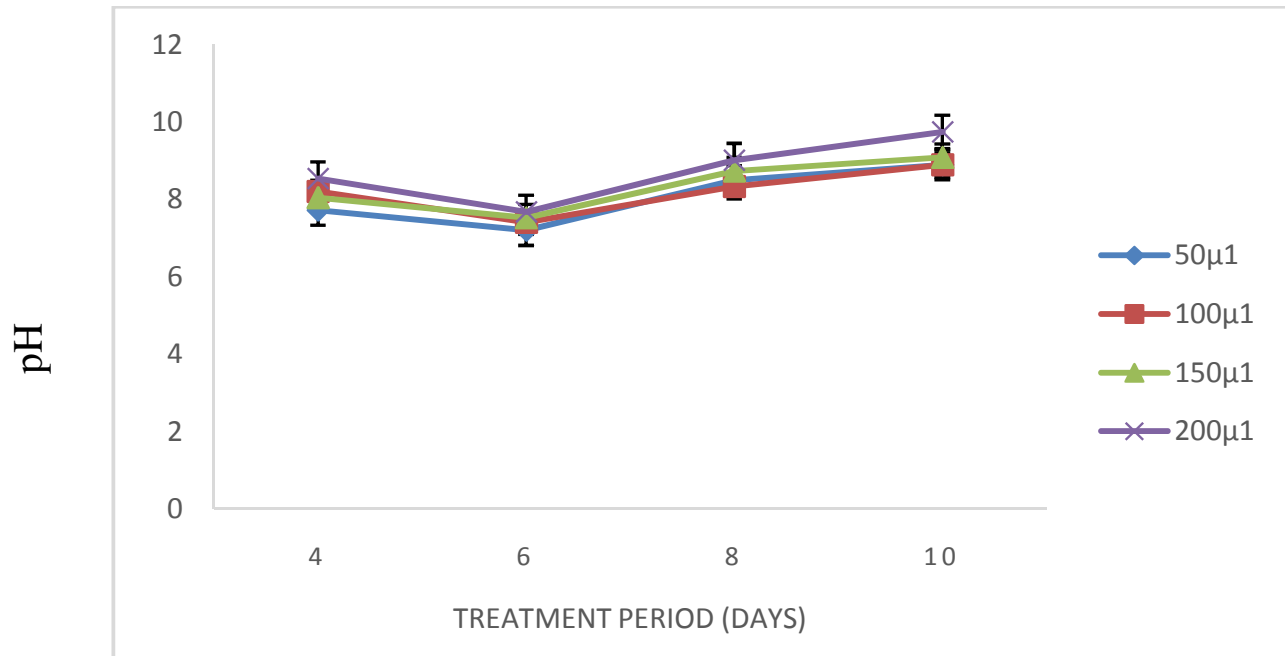

Figure 4: Changes in the $\mathrm{pH}$ of the medium during the degradation of DMF by Bacillus cereus at $40^{\circ} \mathrm{C}$.

Changes in carbon dioxide liberated during the carbon dioxide was observed in the $6^{\text {th }}$ day of degradation of DMF by Bacillus cereus is treatment at $50 \mu \mathrm{l}$ concentration of DMF at $40^{\circ} \mathrm{C}$. illustrated in Figure 5. Highest concentration of

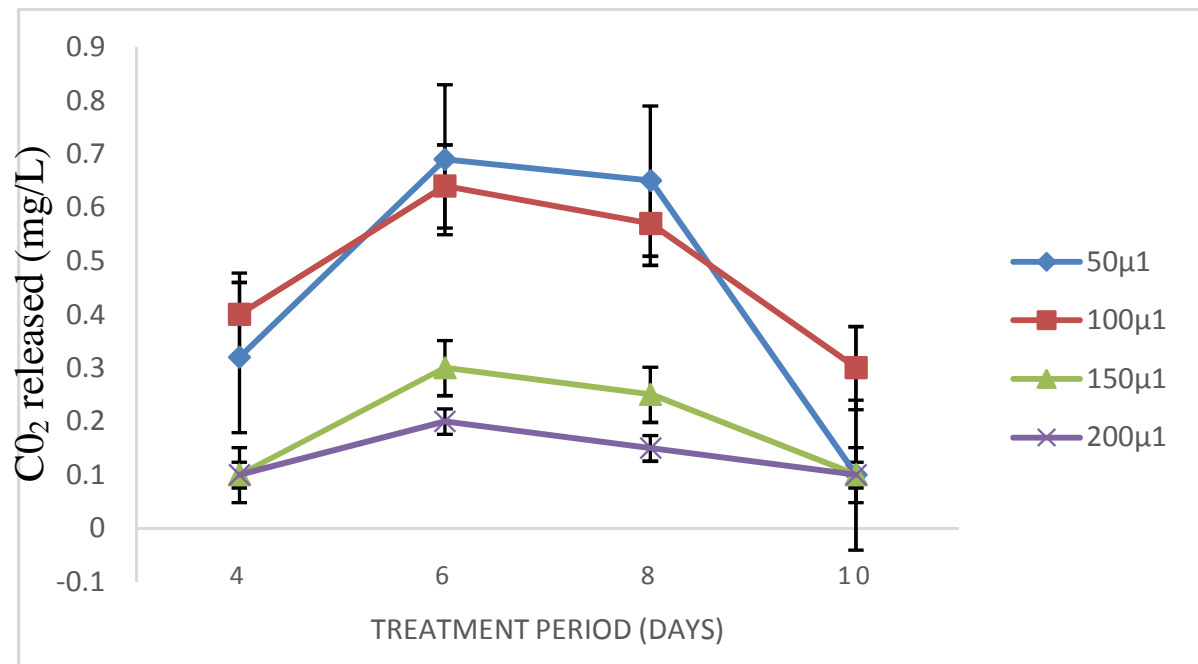

Figure 5: Carbon dioxide released during the degradation of DMF by Bacillus cereus at $40^{\circ} \mathrm{C}$

Changes in Optical density for the biodegradation of DMF by Bacillus cereus, at ambient temperature can be seen in figure 6 an initial increase in Optical density was seen then a decrease was observed. Highest optical density was observed on the $8^{\text {th }}$ day at $150 \mu \mathrm{l}$ concentration of DMF. 


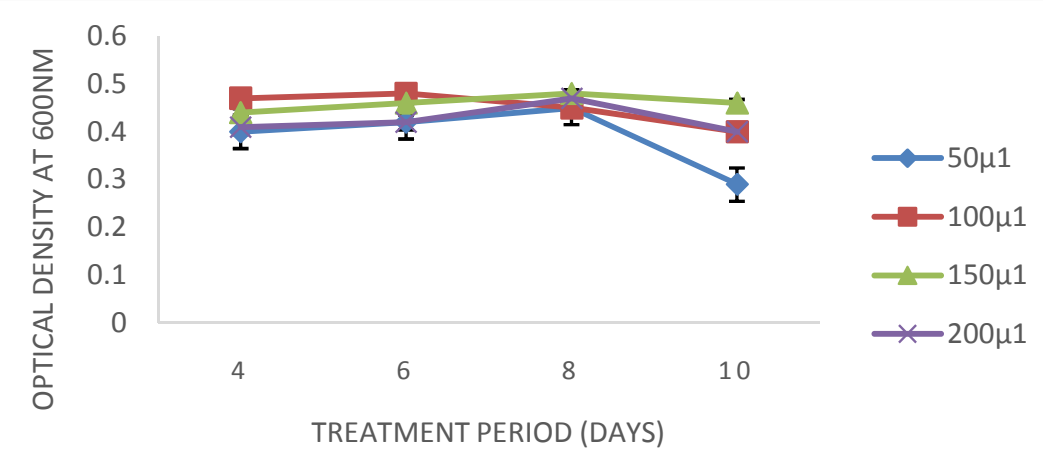

Figure 6: Changes in the optical density during the degradation of DMF by Bacillus cereus at ambient temperature

Changes in $\mathrm{pH}$ determined after 4, 6, 8 and $10^{\text {th }}$ seen in Figure 7 . Highest $\mathrm{pH}$ was observed on $4^{\text {th }}$ day of treatment with Bacillus cereus, can be day (8.92) at 200 $\mu$ l concentration of DMF.

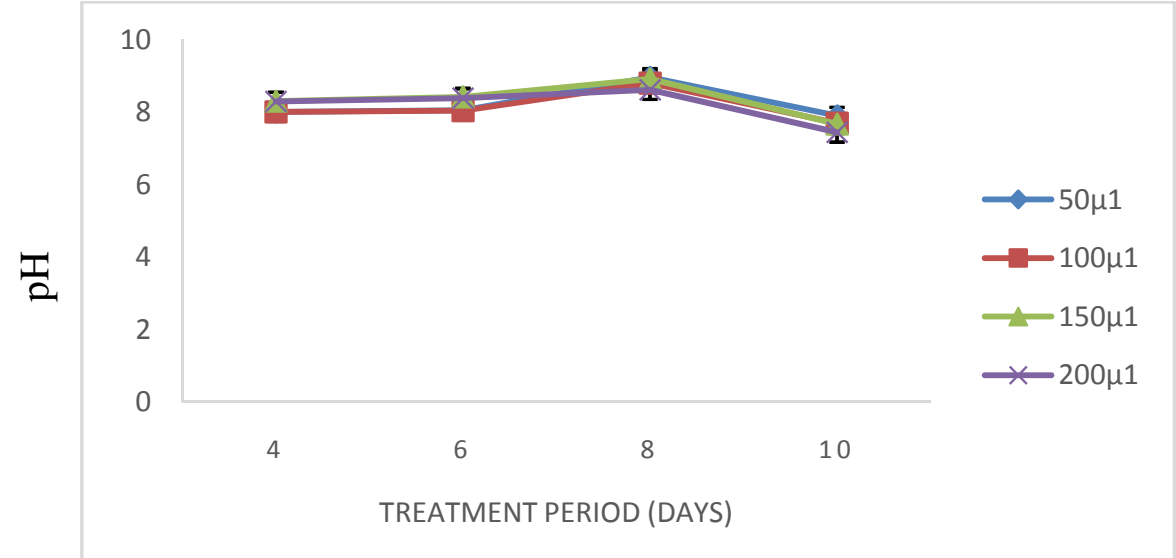

Figure 7: Changes in the $\mathrm{pH}$ of the medium during the degradation of DMF by Bacillus cereus at ambient temperature

Changes in carbon dioxide liberated during the degradation of DMF by Bacillus cereus is illustrated in Figure 8. Highest concentration of carbon dioxide was observed in the $6^{\text {th }}$ day of treatment at $100 \mu \mathrm{LMF}$ at ambient temperature. There was significant difference $(P<0.05)$ in terms of carbon dioxide concentration throughout the duration of the analysis.

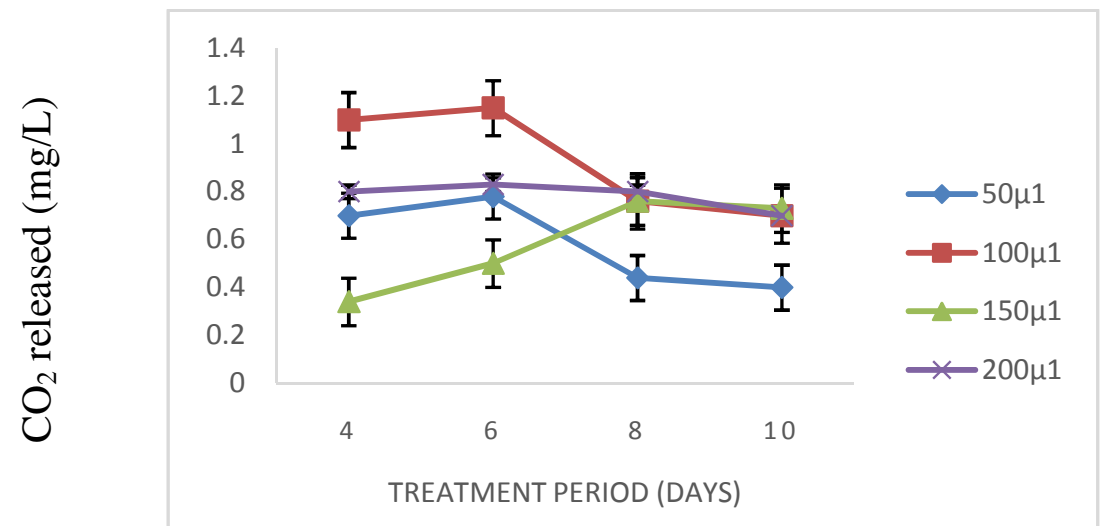

Figure 8: Carbon dioxide released during the degradation of DMF by Bacillus specie at ambient temperature 
Release of ammonia as a result of biodegradation of DMF by Bacillus cereus, is illustrated in figures 9 maximum ammonia concentration was observed on the $4^{\text {th }}$ day at $(1.82 \mathrm{mM}) 50 \mu$ l concentration of
DMF. There was significant difference $(P<0.05)$ in terms of ammonia concentration throughout the duration of the analysis.

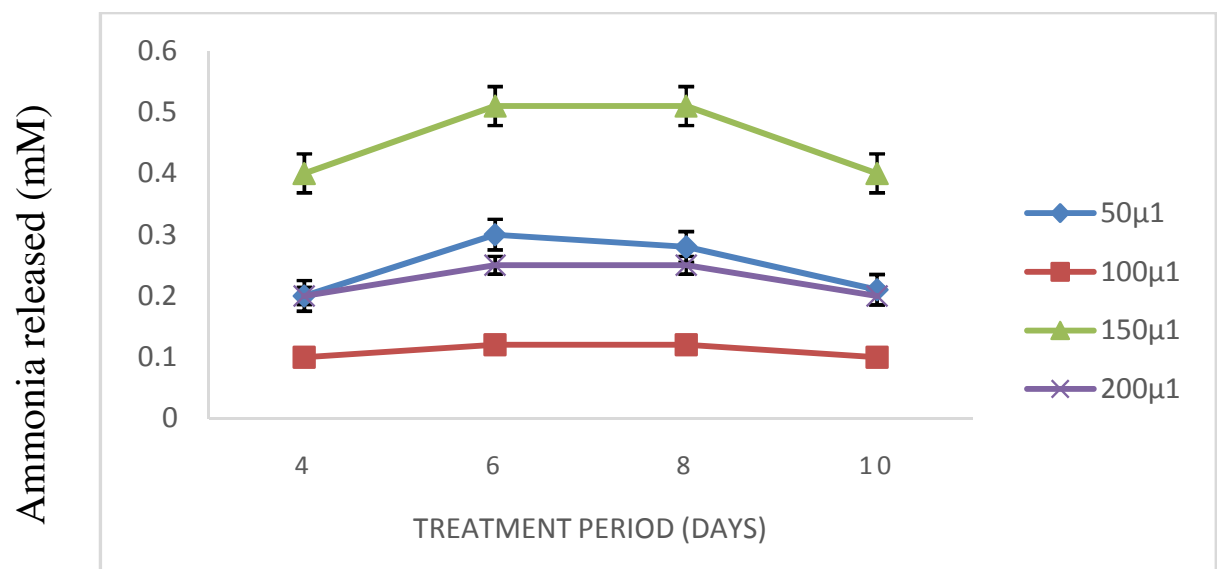

Figure 9: Ammonia released during the degradation of DMF by Bacillus cereus at ambient temperature

Changes in Biomass for the biodegradation of DMF by Bacillus cereus, at ambient temperature can be seen in figure 10 an initial increase in biomass and then a decrease was observed. The increase may be as a result of degradation of DMF and decrease as a result of formation of degraded products like dimethylamine and ammonia. Maximum biomass was observed on the $10^{\text {th }}$ day of treatment at $200 \mu \mathrm{l}$ concentration of DMF. There was no significant difference $(P>0.05)$ in terms of Biomass throughout the duration of the analysis.

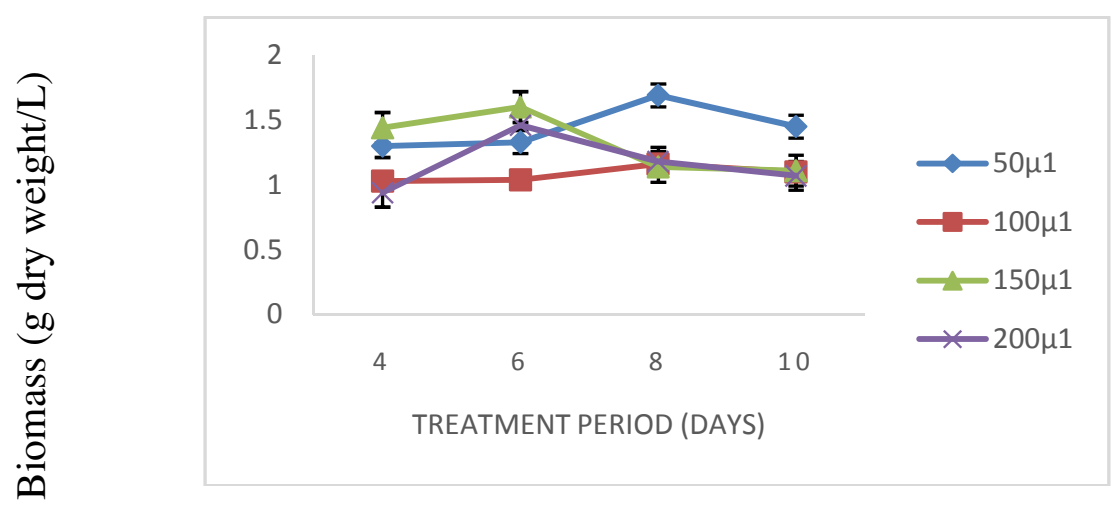

Figure 10: Changes in Biomass during the degradation of DMF by Bacillus specie at ambient temperature

\section{CONCLUSION}

Bacillus cereus was found to be efficient in degrading DMF since it was seen to grow in different concentration of DMF using the textiles chemical as a sole source of carbon.

The biodegradation efficiency was more at $40^{\circ} \mathrm{C}$ than at ambient temperature. This showed that the bacterial isolate can be used in cleaning up Dimethylformamide in textile effluent to save the environment.

\section{Acknowledgment}

The authors thank the authorities of Microbiology Department Laboratory, Central Laboratory complex Bayero University, Kano and Ministry of Water Resources and Pollution Control Kano for the facilities and encouragement. 


\section{REFERENCES}

Bromley-Challenor., K.C.A., Caggiano, N. and Knapp, J.S. (2002). "Bacterial growth on $\mathrm{N}, \mathrm{N}$-dimethylformamide: Implications for the biotreatment of industrial wastewater", Journal of Industrial Microbiology and Biotechnology, 25. 816.

Dojlido, J.R. (1979). Investigations of biodegradability and toxicity of organic compounds. Washington, DC, US Environmental Protection Agency (EPA600/2-79-163)

Ghisalba, O., Cevey, P., Kuenzi, M. and Schär, H.P. (1985). "Biodegradation of chemical waste by specialized methylotrophs, and alternative to physical methods of waste disposal", Conserv Recycl, 8. 47-71.

Kennedy, G.L, and Sherman, H. (1986). "Acute and subchronic toxicity of dimethylformamide and dimethylacetamide following various routes of administration", Drug and chemical toxicology, 9. 147-170.
Long, G., and Meek. (2001). M.E, Concise international chemical assessment. Document 31. World Health Organization, Geneva, 1-61.

Pellizzari, E.O. (1977). The measurement of carcinogenic vapors in ambient atmosphere. Research Triangle Park, NC, US Environmental Protection Agency, Washington DC.

Smyth, H.F., and Carpenter, C.P. (1948). "Further experience with the rangefinding test in the industrial toxicology laboratory", Journal of industrial hygiene and toxicology, 30(1). 63-68.

United States Environmental Protection Agency.(1986). Superfund Public Health Evaluation Manual. EPA/5401/1-86/060, US Environmental Protection Agency, Washington DC.

Vidhya, R., Thatheyus, A.J., (2013). Biodegradation of Dimethylformamide Using Bacillus Cereus. American Journal of Microbiological Research, Vol. 1, No. $1,10-15$. 